\title{
An evaluation of the possibility of water chemical quality restoration at the user by filtration through an activated silica bed
}

\author{
Katarzyna Rucka ${ }^{1, *}$, and Małgorzata Wolska ${ }^{1}$ \\ ${ }^{1}$ Wrocław University of Science and Technology, Faculty of Environmental Engineering, Wybrzeże \\ S. Wyspiańskiego 27, 50-370 Wrocław, Poland
}

\begin{abstract}
The usefulness of activated silica-filled CACF filters from EURO FILTR'EAUX for restoring chemical quality of water delivered to the end user, and therefore limiting scale formation on the surface of devices, and consequently their damage was studied. The study was performed for three different water types, which were characterized by differing hardness and carbo-acidic aggressiveness levels, which allowed an evaluation of the usefulness of the given filtration bed for treating different water types. The study encompassed changes in water chemical stability levels as well as determining the bed useful life. The effect of water-activated silica bed contact on water chemical stability was studied. It was found that filtrates were characterized by greater chemical stability levels than the supplied water, which decreased the risk of scale formation of water installations and decreased water aggressiveness. A decrease in free chloride and dissolved oxygen concentrations was observed, which resulted in a decrease in aggressive water action on water installations.
\end{abstract}

\section{Introduction}

\subsection{Water quality for human consumption}

The requirements for water destined for human consumption in Poland are defined by the Ordinance of the Minister of Health of 13 November 2015 [1] and in generally do not differ from WHO guidelines [2]. Therefore exceeding the limits defined in this ordinance may cause health hazards for consumer. From the moment water leaves the treatment plant until it reaches the consumer, many factors have an effect on its quality, including chemical and biological stability of the transported water [3]. During transport, recontamination occurs, which, among others, causes a deterioration in water taste and smell [4]. The development of biofilms in water pipes and the resultant microorganism diffusion into water results in increased disinfectant consumption, which may yield a significant deterioration in water quality in the water system and the release of corrosion products. On the over hand the disinfectant is necessary to limit of microorganism develop in water. Consequently, the user receives aggressive water, and more rarely with a tendency to deposit calcium carbonate. A lack of water stability delivered to the user and its changed sensory qualities are frequent complaints from customers concerning water quality.

\footnotetext{
* Corresponding author: katarzyna.rucka@pwr.edu.pl
} 
Ensuring chemical water stability limits calcium carbonate precipitation, which increases installation and equipment lifetimes, including heating elements in home appliances.

Due to this, home-based water treatment systems are becoming more common, as they may limit the adverse effects of secondary contamination and ensure chemical and biological stability. The object of this study was an evaluation of the CACF filter with an activated silica bed.

\subsection{Water chemical stability}

Due to the large amount of factors affecting water chemical stability, it is very difficult to unambiguously and precisely determine the effect of water on materials it contacts. Water chemical stability is described by saturation, indicator of the aggressiveness (I), Langelier (IL) or Ryzner (IR) indices, which characterize the calcium-carbonate equilibrium [5]. Values of water indicators which define water as corrosive is presented in the table 1 .

Table 1. Water corrosiveness indicator values.

\begin{tabular}{|c|c|}
\hline Indicator & Value \\
\hline $\mathrm{IL}$ & $<1$ \\
\hline $\mathrm{IR}$ & $>6.8$ \\
\hline $\mathrm{I}$ & $>1$ \\
\hline
\end{tabular}

Besides the calcium-carbonate equilibrium, the water aggressiveness and tendency to release precipitates inside water pipes and installation is decided by many factors. Low $\mathrm{pH}$ and a high water alkalinity may cause an increase in corrosion. The presence of dissolved oxygen and free chlorine in water accelerate corrosion reactions. Dissolved substances cause an increase in conductivity and increase the rate of corrosion [6].

\subsection{CACF Filters}

Many water consumers use home based water treatment systems. From a customer's viewpoint, high chlorine concentrations are important, as they influence the taste of water, along with water hardness, which causes scale deposits on water installations and household appliances. Filters, due to simple installation and the possibility of eliminating chemical substances and bacteria in one device, are most commonly used in households. Different types of filters are in use, making use of reverse osmosis or activated silica beds [7].

Due to its sorbent properties, silica has been used for water treatment for many years. Activated silica is commonly used, and its material properties depend on the activation method and the activating factors [8]. Water-silica contact results in oxygen accumulation around metaloorganic complex, which determines the disinfectant properties of silica [9]. The adsorbing properties of silica are used for softening water, since its surface absorbs calcium and magnesium ions [10]. Activated silica is used in filters mounted close to the water intake, especially for limit water aggressiveness and scale forming potential. For this study a CACF filter was used, produced and commonly used in France. The aim of this 
study was determining and confirming the usefulness of the used filter for treatment of water of varying hardness.

\section{Methods and course of study}

The study was conducted for three internal installations, supplied with water of varying quality and properties. Two of these installations were supplied with surface water supplied to two different cities, while the third installation was supplied with infiltration water. From each installation, two samples were taken: supply and filtrate. The evaluation of water quality included parameters concerning calcium-carbonate equilibrium and oxidant concentrations, which affect the water aggressiveness level. A physio-chemical analysis of water concluded $\mathrm{pH}$ measurement, specific conductivity, general alkalinity, general hardness, calcium, magnesium, iron, free chlorine, diffused oxygen and carbon dioxide concentrations as well as water turbidity. Based on these measurements, aggressive carbon dioxide content was determined, along with water aggressiveness and corrosivity indicators.

Table 2 presents a list of Polish Standards used in the analysis of water quality parameters.

Table 2. List of Polish Standards used in the analysis of water quality parameters.

\begin{tabular}{|c|c|c|c|}
\hline Indicator & Unit & $\begin{array}{c}\text { Method of } \\
\text { determination }\end{array}$ & Standard \\
\hline $\mathrm{pH}$ & & Potentiometric & ISO 5969 \\
\hline Alkalinity & $\mathrm{val} / \mathrm{m}^{3}$ & Titration & PN-EN ISO 9963-1:2001/Ap1:2004 \\
\hline $\mathrm{CO}_{2 \mathrm{~F}}$ & $\mathrm{gCO}_{2} / \mathrm{m}^{3}$ & Metotitration & $\begin{array}{c}\text { PN-C-04547-01:1974 } \\
\text { PN-C-04547-03:1974 }\end{array}$ \\
\hline Turbidity & $\mathrm{NTU}$ & Nephelometric & PN-EN ISO 7027:2003 \\
\hline Dissolved Oxygen & $\mathrm{g} \mathrm{O}_{2} / \mathrm{m}^{3}$ & Potentiometric & PN-EN 25814:1999 \\
\hline Free chlorine & $\mathrm{g} \mathrm{Cl}^{3}$ & DPD & PN-EN 937:2009 \\
\hline Specific conductivity & $\mu \mathrm{SS} / \mathrm{cm}^{3}$ & Direct measurement & PN-EN 27888:1999 \\
\hline Hardness & $\mathrm{g} \mathrm{Pt} / \mathrm{m}^{3}$ & Titration with EDTA & PN-ISO 6059:1999 \\
\hline Calcium & $\mathrm{g} \mathrm{Ca} / \mathrm{m}^{3}$ & Titration with EDTA & PN-ISO 6058:1999 \\
\hline Magnesium & $\mathrm{g} \mathrm{Mg} / \mathrm{m}^{3}$ & Titration with EDTA & PN-C-04554-04:1999 Ap.A \\
\hline Iron & $\mathrm{g} \mathrm{Fe} / \mathrm{m}^{3}$ & FAAS & PN-ISO 8288:2002 \\
\hline
\end{tabular}

An evaluation of the effects of water-filtration bed contact were performed based on the differences in the calculated indicators and carbon dioxide content in the filtrate. The calcium carbonate (scale) precipitation potential was determined based on changes in the values of $\mathrm{pH}$, turbidity, water hardness and carbon dioxide concentration.

For the installation supplied with infiltration water, the bed useful life was also determined, taking the end of bed capacity as the moment when filtrate quality parameters deteriorated. The flow characteristic determination was performed based on the differences 
in pressure measurements before and after the filter and the amount of water that flowed through the filter. This was possible due to a flow meter installed on the installation and manometers before and after the filter.

The study was conducted for one and a half months, with water samples taken once a week. For the installation supplied with infiltration water, the study was conducted up to the moment of end of bed capacity.

\section{Results}

All the water supplies had an average hardness, though the largest values were exhibited by surface water from water supply 1 (Table 3 ).

In the majority of samples from all three water supplies, aggressive carbon dioxide was present, which testified to aggressive character of water. Surface water from supply 1 was characterized by the highest concentration of this gas and the greatest water alkalinity.

All three water sources fulfilled the requirements for water for human consumption, apart from turbidity (Fig.1), whose exceedances were probably connected with the presence of deposits inside water pipes and the flushing of these deposits during non-uniform water usage periods. Such a dependency was also found by Barbot et al. [11].

In all the water supply samples, dissolved oxygen was present, and in water from sources 2 and 3, free chlorine was also present, increasing water aggressiveness.

The greatest iron content was found from infiltration water from supply 3 . In general the water being supplied to each installation differed in aggressiveness levels and insoluble contaminant content, which decided water turbidity levels. A lack of water chemical stability is testified to by the values of the water aggressiveness indicators (Table 3 ) and the presence of oxidants and aggressive carbon dioxide. Therefore, it was reasonable to use these water supplies for studies of changes in water chemical stability levels due to flow through activated silica filtration beds.

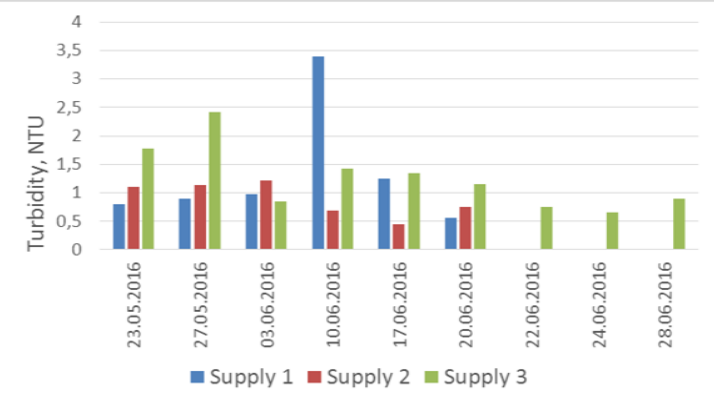

Fig. 1. Water supply turbidity.

Due to water-filtration bed contact an increase in $\mathrm{pH}$ values was found in all filtered water samples from all three installations. The increase in $\mathrm{pH}$ values was accompanied by an increase in alkalinity for water from supply 1, which was in the range of $0.05-0.5 \mathrm{val} / \mathrm{m}^{3}$, and it increased with filter bed usage time and at the final period of the study was equal to $0.1 \mathrm{val} / \mathrm{m}^{3}$. However, no change or an increase in this parameter was found for water from the two other installations. The difference in changes in this parameter probably results from different aggressiveness of the supply waters.

It is significant from a chemical stability standpoint that no change in water hardness was found in any of the filtrates, which leads to the hypothesis the increase in water 
stability results from a change in contaminant form and not content. This hypothesis is confirmed by the increase in water specific conductivity in all filtrate samples, which differed depending on water type (Fig. 2).

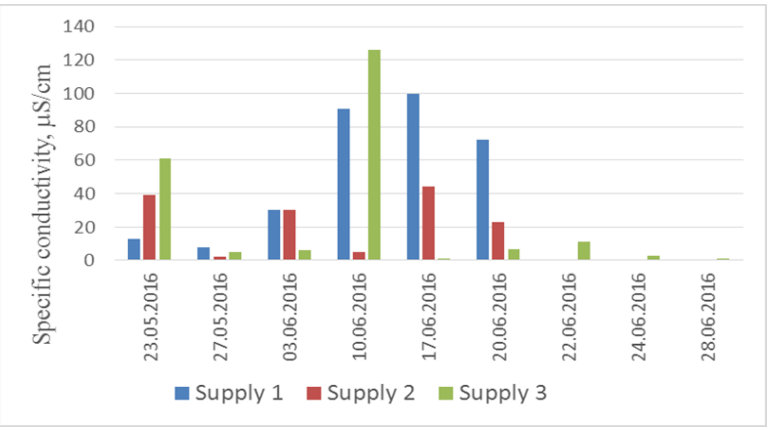

Fig. 2. Increased in water specific conductivity caused by contact with activated silica bed.

Furthermore, an increase in water chemical stability is testified to by the decrease in aggressive carbon dioxide that was found and amounted to $134 \mathrm{~g} \mathrm{CO}_{2 \text { agrr }} / \mathrm{m}^{3}, 3.5 \mathrm{~g}$ $\mathrm{CO}_{2 \text { agrr }} / \mathrm{m}^{3}$ and $5.8 \mathrm{~g} \mathrm{CO}_{2 \text { agrr }} / \mathrm{m}^{3}$ respectively for water supplies 1,2 and 3. Consequently, the concentration of this gas found in filtrates was much smaller, and in the majority of samples no presence of it was detected.

Contact with a activated silica also ensured a decrease in chlorine content in all water samples, however its concentration in filtrates from supplies 2 and 3 was in the range of 0.07-0.43 $\mathrm{g} \mathrm{Cl}_{2} / \mathrm{m}^{3}$ and 0.22-0.36 $\mathrm{g} \mathrm{Cl}_{2} / \mathrm{m}^{3}$ respectively. A decrease in chlorine concentration was accompanied by decreases in oxygen content (fig.3). Probably the oxidants were absorbed by active silica which is good adsorbent.

A consequence of the decrease in aggressive carbon dioxide and oxidant content was a decrease in water aggressiveness and a restoration of calcium-carbonate equilibrium, which is testified by the calculated water corrosiveness indicators. In all filtrate samples, lower values of IR and I indices were found, along with IL changes indicating a decrease in water aggressiveness levels.

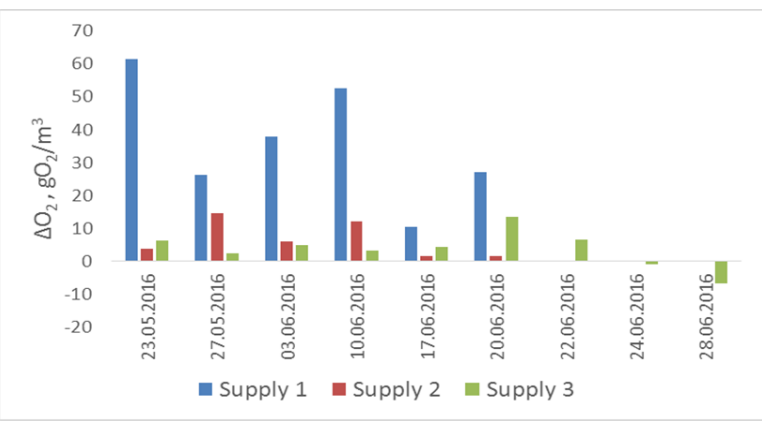

Fig. 3. Effectiveness of dissolved oxygen removal during water filtration.

Apart from a decrease in water aggressiveness, a decrease in non-soluble contaminant content was observed, measured as turbidity. The effectiveness in decreasing this parameter was in the range of: $2.2-80.9 \%, 19.7-58.1 \%$ and $8.2-64.3 \%$ respectively for supplies 
1, 2 and 3. Among the suspended contaminants that were removed were iron compounds, whose concentrations were effectively lowered in all waters.

For water supply 3, the filter useful life was determined. Studies were conducted until the end of filtration bed capacity. The end of bed capacity caused a lack of increase in specific conductivity and a smaller increase in $\mathrm{pH}$ and an increase in calcium ion content, which testified to flushing of contaminants from the bed. An increase in dissolved oxygen was also observed along with a lack of change in free chlorine concentrations. The end of bed capacity occurred after obtaining $147 \mathrm{~m}^{3}$ of filtrate. In order to confirm the end of bed capacity, tests of increase in flow resistance at three filtrate flow volumes through the bed were conducted (Fig.4).

Based on this analysis, it may be stated that despite a large volume of filtrate that had flowed through bed, the increase in resistance and therefore the decrease in supply valve efficiency, was insignificant. It may be concluded that the limiting factor in determining the end of bed useful life is not water flow hydraulics, but a changes in filtrate quality.

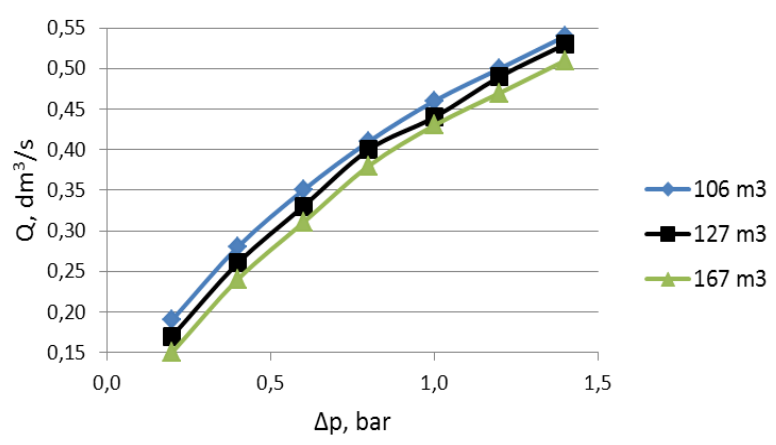

Fig. 4. Effect of volume of water filtered through the bed on changes in supply valve efficiency. 


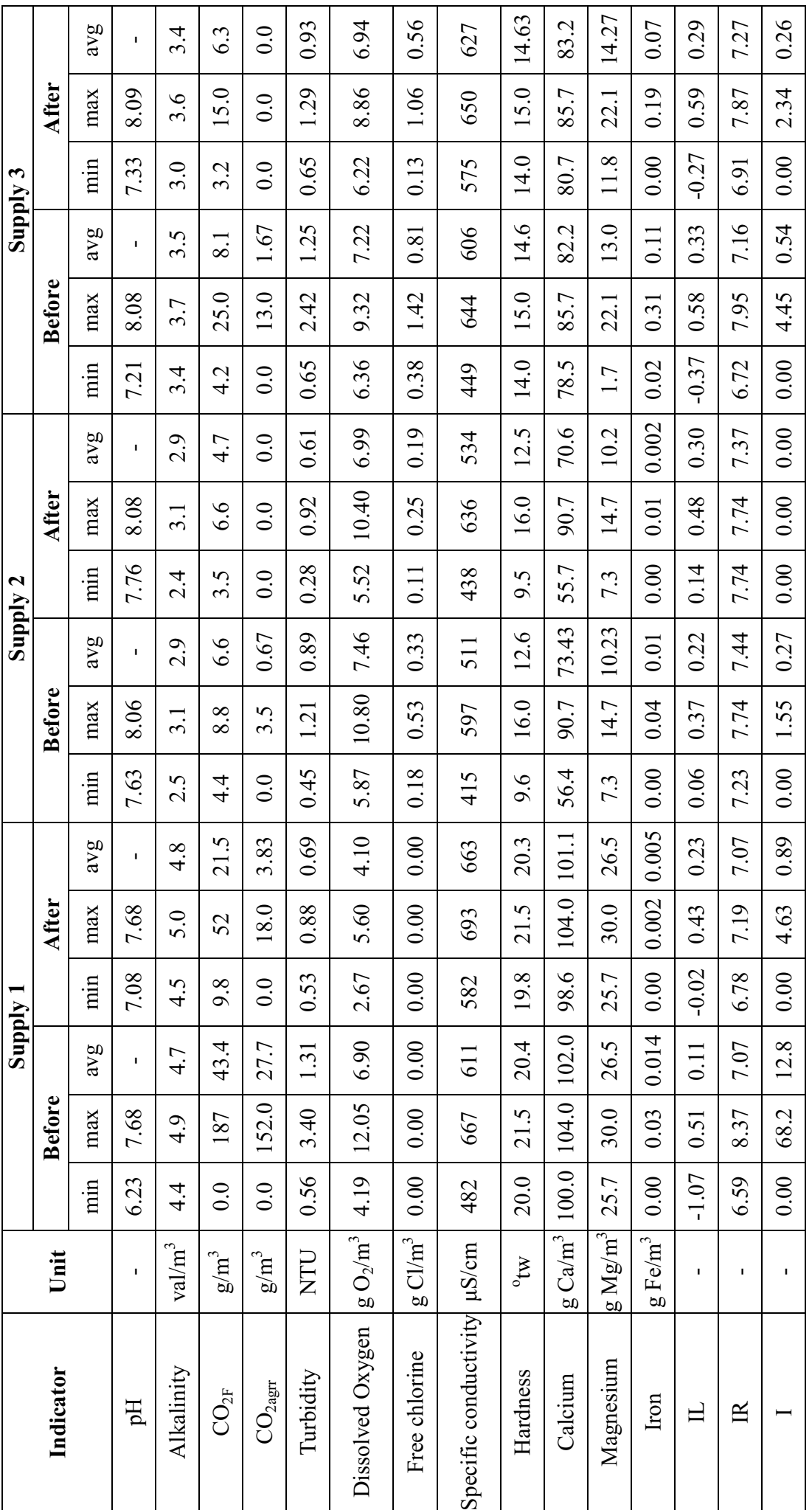




\section{Conclusions}

An evaluation of water quality before and after filtration allowed for posing the following conclusions

1. The quality of all filtrate water samples fulfilled the requirements for water for human consumption, with the exception of turbidity.

2. Filtrates were characterized with a greater chemical stability level than the supply water, which decreased the potential for scale formation in water pipes and household appliances, and limited the water aggressiveness level.

3. A decrease in dissolved oxygen concentration and free chlorine contributed to a lowering of the aggressive effects on water pipes.

4. Lowering of free chlorine concentration causes an improvement in the taste and olfactory qualities of water.

5. Contact with the filtration bed caused a decrease in turbidity and iron concentration, which allows for fulfilling the requirements for water for human consumption.

6. Studies have confirmed the manufacturer's data concerning the volume of water that can flow before bed capacity is reached. The end of bed capacity is decided by worsening filtrate quality and not increasing flow resistance

7. The filtrate quality worsens gradually after the end of bed capacity, and not suddenly as is the case if there is intense contaminant flushing from the filtration bed.

\section{References}

1. Ordinance of the Minister of Health of 13 November 2015, Dz.U.2015.1989 date 2015.11.27

2. World Health Organization. Guidelines for drinking-water quality [electronic resource]: incorporating first addendum. Vol. 1, Recommendations - 3rd edition 2006.

3. M. Świderska-Bróż, Ochr. Sr. 25, 4 (2003)

4. M.J. Lethola, M. Laxander, I.T. Miettinen, A. Hirvonen, T. Vartiainen, P.J. Martikainen, Water Res. 40, 1 (2006)

5. M. Esmaeili-Vardanjani, I. Rasa, V. Amiri, M. Yazdi, K. Pazand, Environ. Monit. Assess. 187, 53 (2015)

6. N.C. Burtch, H. Jasuja, K.S. Walton, Chem. Rev. 114, 20 (2014)

7. http://www.woda.com.pl

8. Surface Active Silica Sols Effect of PEG-Silica Interactions, Department of Chemical and Biological Engineering, Division of Applied Surface Chemistry, Chalmers University of Technology Goteborg, Sweden (2011)

9. M. Laskowska, Ł. Laskowski, K. Fijałkowski, M. Kacprzak, Inżynieria Materiałowa 35, 6 (2014) (in Polish)

10. A. Szkatula, M. Balanda, M. Kopeć, The European Physical Journal of Applied Physics 18, 1 (2002)

11. E. Barbot, N.S. Vidic, K.B. Gregory, R.D. Vidic, Environ. Sci. Tech. 47, 6 (2013) 